\title{
Mice lacking NF-kB1 exhibit marked DNA damage responses and more severe gastric pathology in response to intraperitoneal tamoxifen administration
}

\author{
Michael D Burkitt ${ }^{1}$, Jonathan M Williams ${ }^{2}$, Tristan Townsend ${ }^{1}$, Rachael Hough ${ }^{1}$ and D Mark Pritchard ${ }^{\star, 1}$
}

Tamoxifen (TAM) has recently been shown to cause acute gastric atrophy and metaplasia in mice. We have previously demonstrated that the outcome of Helicobacter felis infection, which induces similar gastric lesions in mice, is altered by deletion of specific NF- $K B$ subunits. Nfkb1 $1^{--}$mice developed more severe gastric atrophy than wild-type (WT) mice 6 weeks after H. felis infection. In contrast, $\mathrm{Nfkb2}^{-/-}$mice were protected from this pathology. We therefore hypothesized that gastric lesions induced by TAM may be similarly regulated by signaling via NF- $\kappa$ B subunits. Groups of five female C57BL/6 (WT), Nfkb1 ${ }^{-/}$, Nfkb2 ${ }^{--}$and $c-\mathrm{Re}^{-/}$mice were administered $150 \mathrm{mg} / \mathrm{kg}$ TAM by IP injection. Seventy-two hours later, gastric corpus tissues were taken for quantitative histological assessment. In addition, groups of six female WT and Nfkb1 $1^{-/-}$mice were exposed to 12 Gy $\gamma$-irradiation. Gastric epithelial apoptosis was quantified 6 and $48 \mathrm{~h}$ after irradiation. TAM induced gastric epithelial lesions in all strains of mice, but this was more severe in $\mathrm{Nfkb}^{-/-}$mice than in WT mice. $\mathrm{Nfkb} 1^{-/-}$mice exhibited more severe parietal cell loss than WT mice, had increased gastric epithelial expression of Ki67 and had an exaggerated gastric epithelial DNA damage response as quantified by $\gamma \mathrm{H} 2 \mathrm{AX}$. To investigate whether the difference in gastric epithelial DNA damage response of $\mathrm{Nfkb} 1^{-/-}$mice was unique to TAM-induced DNA damage or a generic consequence of DNA damage, we also assessed gastric epithelial apoptosis following $\gamma$-irradiation. Six hours after $\gamma$-irradiation, gastric epithelial apoptosis was increased in the gastric corpus and antrum of $\mathrm{Nfkb}^{-/-}$ mice. NF- $\kappa B 1$-mediated signaling regulates the development of gastric mucosal pathology following TAM administration. This is associated with an exaggerated gastric epithelial DNA damage response. This aberrant response appears to reflect a more generic sensitization of the gastric mucosa of $\mathrm{Nfkb}^{-/-}$mice to DNA damage.

Cell Death and Disease (2017) 8, e2939; doi:10.1038/cddis.2017.332; published online 20 July 2017

Gastric cancer in humans is strongly associated with gastric colonization with Helicobacter pylori. ${ }^{1}$ This leads, in a minority of people, to a preneoplastic cascade of pathology that develops over several decades. This cascade is typified by gastric oxyntic gland atrophy, epithelial metaplasia, dysplasia and cancer. $^{2}$ These events can be modeled by infecting C57BL/6 mice with the related bacterium Helicobacter felis. In this model, advanced gastric preneoplasia develops over 12 months and, in some hands, malignancies have been reported in animals aged 13-15 months.,4

The development of gastric preneoplasia in response to gastric Helicobacter infection occurs on the background of chronic inflammation of the gastric mucosa. The signaling pathways that regulate gastric epithelial remodeling in response to chronic inflammation are complex and have not been fully elucidated. However, there is a wealth of evidence that signaling through NF- $K \mathrm{~B}$ pathways is involved in the development of inflammation-associated malignancies both in the stomach and in other parts of the gastrointestinal tract. ${ }^{5}$ The NF- $k B$ proteins are a group five of structurally related transcription factors (RelA (p65), RelB, c-Rel, NF-kB1 (p50) and NF- $k$ B2 (p52)), which influence transcription through the binding of homodimer or heterodimers of themselves to chromatin. Activation of transcription through these proteins is tightly regulated, both through a network of upstream signaling kinases and by complex posttranscriptional modification of the NF- $\kappa$ B subunits. Two distinct NF- $\kappa$ B pathways are conventionally described: the classical (canonical) pathway is regulated by the activation of $\mathrm{IKK} \beta$, following stimuli including TNF binding to its receptor, and activation of Toll-like receptors. The principal NF- $\kappa \mathrm{B}$ dimers activated by this pathway are RelA/NF- $k$ B1 dimers and RelA/c-Rel dimers. In contrast, the alternative (non-canonical) NF- $k \mathrm{~B}$ signaling pathway is regulated by the kinase NIK and is characterized by transcriptional regulation by dimers of RelB/NF- $\kappa \mathrm{B} 2$ (see Merga et al. ${ }^{5}$ for a recent review of these pathways).

We have previously reported that $H$. felis-induced gastric preneoplasia is differentially regulated by signaling involving specific NF- $k$ B subunits. Mice lacking the NF- $k$ B1 subunit developed more severe gastric atrophy after 6 weeks of infection and more severe preneoplastic pathology when infected for 12 months. In contrast, $N f k_{b 2}{ }^{-/}$mice were entirely protected from $H$. felis-induced pathology, despite heavy colonization by these bacteria. ${ }^{6}$ This has also been demonstrated in the context of acute inflammatory responses in the intestinal tract where $N k_{k b 2^{-/-}}$mice exposed to low-dose

\footnotetext{
${ }^{1}$ Department of Cellular and Molecular Physiology, Institute of Translational Medicine, University of Liverpool, The Henry Wellcome Laboratory, Liverpool, UK and ${ }^{2}$ Pathology and Pathogen Biology, Royal Veterinary College, North Mymms, UK

*Corresponding author: DM Pritchard, Department of Cellular and Molecular Physiology, Institute of Translational Medicine, University of Liverpool, The Henry Wellcome Laboratory, Nuffield Building, Crown St., Liverpool L69 3GE, UK. Tel: +44 015179455 63; Fax: +44 151706 5832; E-mail: mark.pritchard@liverpool.ac.uk

Received 01.3.17; revised 14.6.17; accepted 15.6.17; Edited by T Kaufmann
} 
lipopolysaccharide systemically were protected from pathological small intestinal villus tip epithelial cell shedding and apoptosis, whereas $\mathrm{Nfkb} 1^{-1-}$ mice demonstrated more severe lesions than wild-type (WT) mice. $^{7}$

It has recently been reported that intraperitoneal administration of tamoxifen to mice induces an acute gastric corpus metaplasia, characterized by the loss of parietal cells, metaplastic changes originating in the chief cells at the base of the gastric glands and increased epithelial cell proliferation. ${ }^{8}$ These findings have been shown to be reproducible in other laboratories, ${ }^{9}$ to be estrogen independent and reversible on discontinuation of tamoxifen. Unlike $H$. felis-induced gastric preneoplasia, this pathology occurs with relatively little associated inflammation in the gastric mucosa; ${ }^{10}$ this model therefore offers an opportunity to investigate gastric epithelial remodeling in the absence of a chronic inflammatory stimulus.

We have utilized this model to characterize whether the regulation of gastric preneoplasia by mice lacking specific NF- $k \mathrm{~B}$ subunits is a generic response to gastric epithelial remodeling or specific to the events induced by $H$. felis infection.

\section{Results}

Tamoxifen induced gastric corpus pathology is regulated by Nfkb1. To characterize whether deletion of specific NF- $k B$ subunits altered the severity of pathology induced by administration of tamoxifen, groups of at least five, 12-week old, WT, $\mathrm{Nfkb1}^{-/-}, \mathrm{Nfkb2^{-/ }}$ and $\mathrm{c}-\mathrm{Re}^{-/-}$female mice were either treated with tamoxifen or vehicle and culled $72 \mathrm{~h}$ later. Gastric pathology was scored using an established scoring system. ${ }^{11}$ Vehicle-treated mice of all genotypes exhibited minimal gastric lesions (Figures 1 and 2a). Following administration of tamoxifen, morphological changes were seen in the corpus mucosa of all groups of mice. Tamoxifentreated WT mice had mean pathology scores of $2.4( \pm 0.51$ S.E.M.). Nfkb2 ${ }^{-/}$and $c-R e l^{-1}$ mice exhibited similar lesion scores, while $\mathrm{Nfkb1}^{-1-}$ mice exhibited more severe gastric lesions with a mean score of $4.8( \pm 0.74, P<0.01$ by two-way analysis of variance (ANOVA) and Dunnett's post hoc test).

To quantify the degree of gastric atrophy induced by tamoxifen, we assessed the number of $\mathrm{H}^{+} / \mathrm{K}^{+}$ATPaseexpressing cells. Among untreated mice, no significant differences in the number or distribution of parietal cells were identified between the mice of different genotypes. In all, $31.2 \%$ of cells in the gastric corpus of untreated WT mice expressed $\mathrm{H}^{+} / \mathrm{K}^{+}$ATPase (Figures 1 and $2 \mathrm{~b}$ ), and cells were distributed between cell positions 2 and 36 of the gastric gland, with peak prevalence at cell position 15 (Figure 2c).

Following administration of tamoxifen, the number of $\mathrm{H}^{+}$/ $\mathrm{K}^{+}$ATPase-expressing cells did not differ substantially in WT mice, but a shift in parietal cell distribution up the gland was noted (significantly higher numbers of parietal cells observed between cell positions 18 and 36 in tamoxifen-treated mice, $P<0.05$ by modified median testing, Figure $2 \mathrm{c}$ ). In keeping with the visual analog scoring of gastric lesions, similar numbers and distributions of $\mathrm{H}^{+} / \mathrm{K}^{+}$ATPase-expressing cells were identified in the corpus of $\mathrm{Nfkb2}^{-/}$and $\mathrm{c}-\mathrm{Re}^{-/}$mice that had been exposed to tamoxifen (Figures $2 b$, e and $f$ ). In contrast, $\mathrm{Nfkb} 1^{-/}$mice showed more marked changes in parietal cell distribution than their WT counterparts, with a 2.4fold reduction in parietal cell number $(P<0.001$ by two-way ANOVA and Dunnett's post hoc analysis, Figure $2 \mathrm{~b}$ ), and a marked reduction in parietal cell abundance between cell
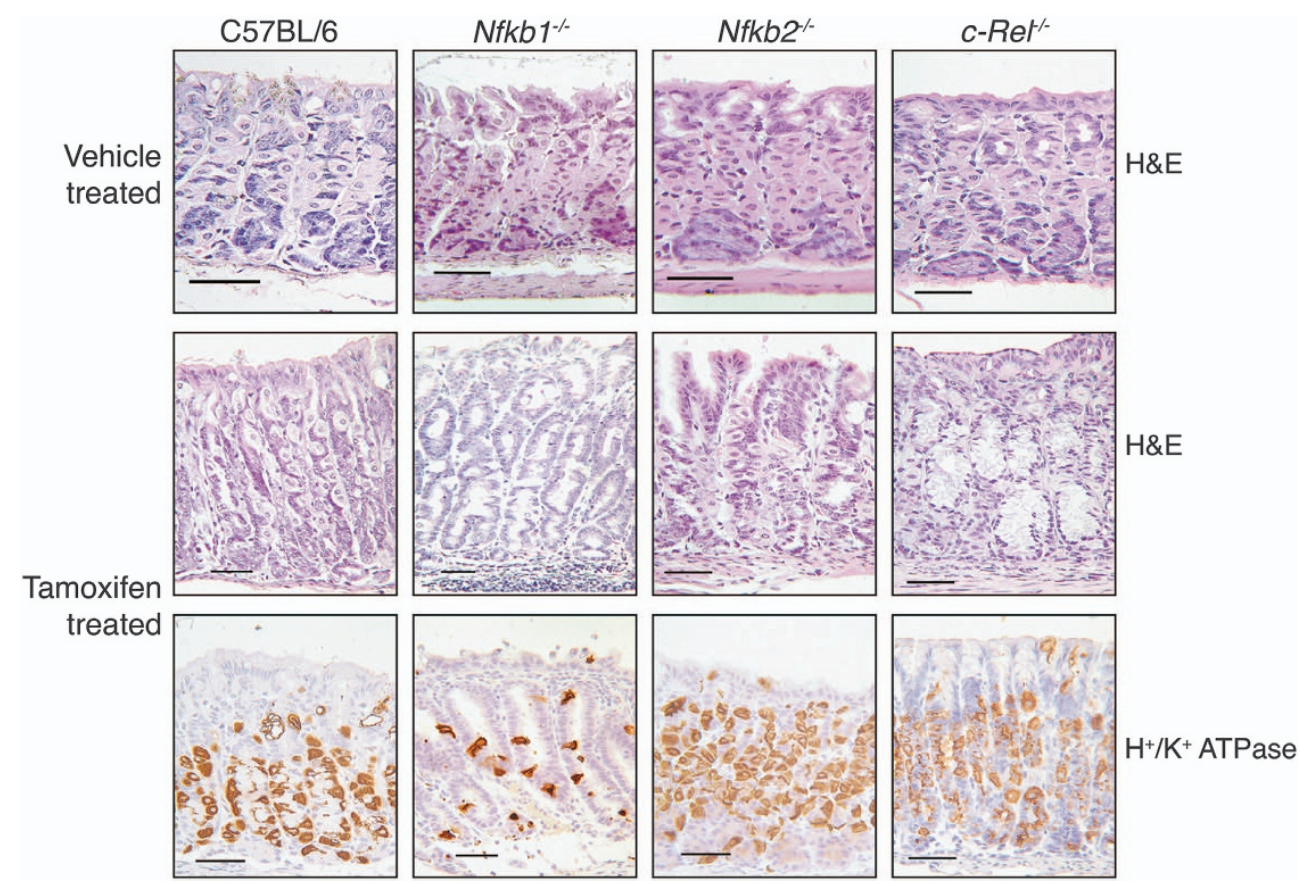

Figure 1 Representative photomicrographs of gastric corpus of WT, $\mathrm{Nfkb}^{-/-}, \mathrm{Nfkb2^{-- }}$ and $\mathrm{c}-\mathrm{Re}^{-/}$mice treated with vehicle or $150 \mathrm{mg} / \mathrm{kg}$ tamoxifen. Sections stained with hematoxylin and eosin or immunostained for the expression of $\mathrm{H}^{+} / \mathrm{K}^{+} \mathrm{ATP}$ ase. Scale bars $100 \mu \mathrm{m}$ 
a

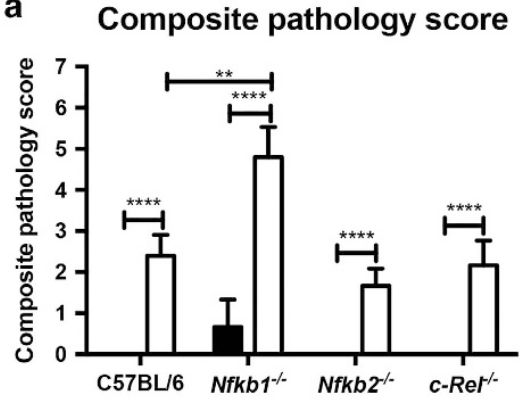

C

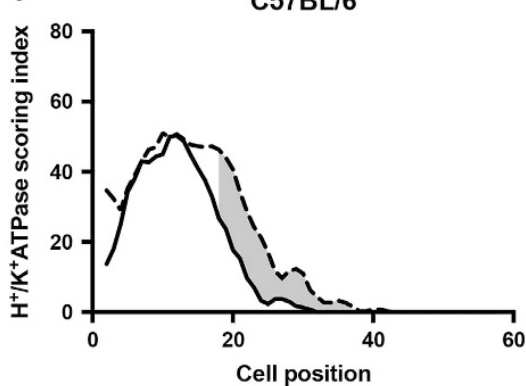

e

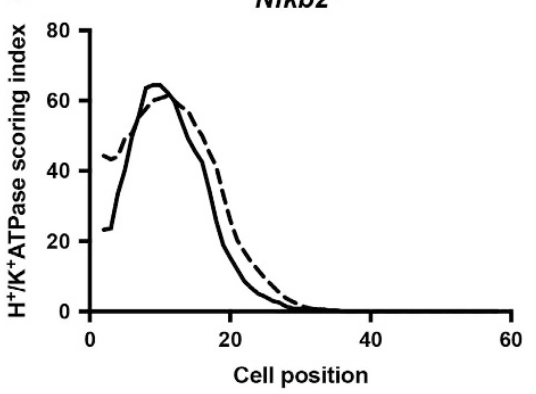

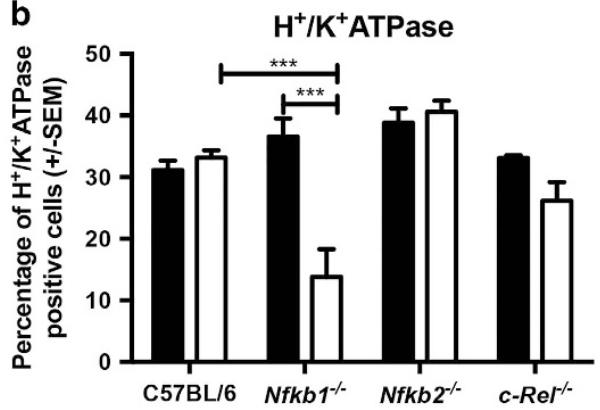

d

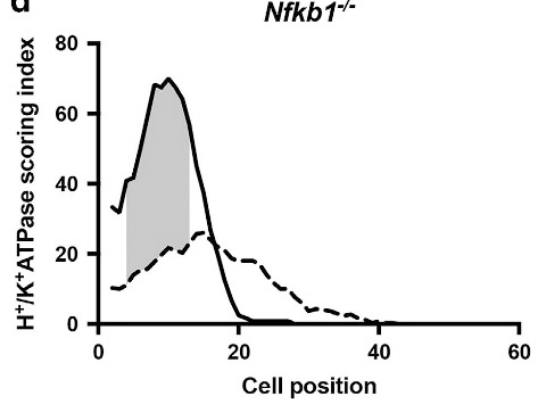

f

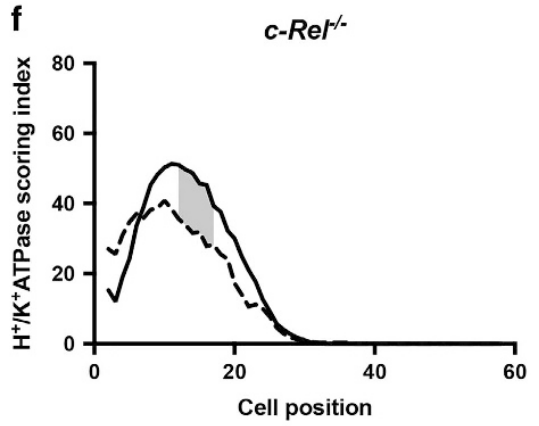

Tamoxifen treated

Vehicle treated

- Vehicle treated

- - Tamoxifen treated

Figure 2 Tamoxifen-induced epithelial lesions in WT, $\mathrm{Nfkb}^{-/-}, \mathrm{Nfkb}^{-/-}$and $\mathrm{c}-\mathrm{ReF}^{-1}$ mice. (a) Visual analog scoring of pathology identified in hematoxylin and eosinstained sections from mice treated with vehicle or $150 \mathrm{mg} / \mathrm{kg}$ tamoxifen. (b) Percentage of gastric corpus gland cells expressing $\mathrm{H}^{+} / \mathrm{K}^{+}$ATPase in mice treated with vehicle or $150 \mathrm{mg} / \mathrm{kg}$ tamoxifen. For panels ( $\mathbf{a}$ and $\mathbf{b}$ ), statistically significant differences tested by two-way ANOVA and Dunnett's test. ${ }^{* \star} P<0.01,{ }^{* * *} P<0.001$, ${ }^{* \star * \star} P<0.0001$. (c-f):

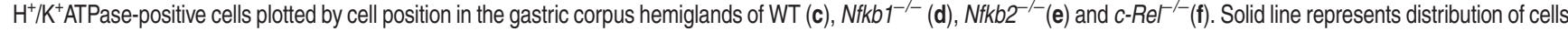

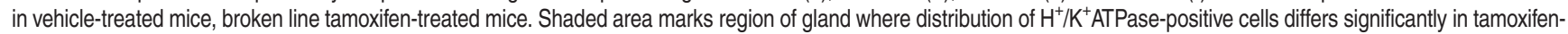
treated versus vehicle-treated mice, $P<0.05$ by modified median test. $N=5$ for all experimental groups

positions 4 and 13 of gastric corpus glands $(P<0.05$ by modified median testing, Figure $2 \mathrm{~d}$ ). To validate this observation and to determine whether the observed effects of tamoxifen were likely due to an estrogen receptor-mediated effect, we performed quantitative real-time PCR on gastric mucosal samples from WT and $N f k b 1^{-1}$ mice that had or had not been treated with tamoxifen. These assays demonstrated reduced transcription of ATP4A (encoding $\mathrm{H}^{+} / \mathrm{K}^{+}$ATPase) in tamoxifen-treated WT and $\mathrm{N} f k b 1^{-/-}$mice but no differences in the expression of estrogen receptor-regulated genes Erbb2 or Wnt5A (Supplementary Figure 1).

Nfkb1-mediated signaling regulates tamoxifen-induced cell proliferation. To determine whether NF- $k B$ signaling influenced gastric epithelial cell turnover following the administration of tamoxifen, we quantified cells expressing the S-phase marker Ki67 and those undergoing apoptosis by the expression of cleaved caspase 3 .

In untreated mice, genotype did not significantly influence the number of cleaved caspase 3-positive cells, which were relatively rare occurrences $(1.4 \pm 0.68$ S.E.M. cells per high-power $(\times 40$ objective) field). However, there was a trend toward more apoptosis in both $\mathrm{Nfkb1^{-/ }}$ and $\mathrm{Nfkb2}^{-1-}$ mice. Administration of tamoxifen to WT mice increased the number of cleaved caspase 3-positive cells 3.4-fold, but this did not reach statistical significance (Figures $3 \mathrm{a}$ and b). In both $\mathrm{Nfkb1^{-1 }}$ and $\mathrm{Nfkb2}-1-$ mice, tamoxifen induced apoptosis in a larger number of apoptotic cells than in WT mice (3.9- and 4.8-fold, $P<0.05$ and $P<0.01$, respectively). 
In untreated WT mice, $18.1 \%( \pm 0.7)$ of gastric corpus epithelial cells were in $\mathrm{S}$ phase. They were distributed between cell positions 5 and 32; peak proliferative index was observed at cell positions 15 and 16 . Proliferating cells were more abundant in untreated $\mathrm{Nfkb}^{-/-}$mice, compared with WT $(26.6 \% \pm 1.9$, $P<0.05$ by two-way ANOVA and Dunnett's post hoc test); in this genotype, peak proliferative index was observed at cell position 14, and proliferating cells were observed between cell positions 2 and 29. Other untreated transgenic mice exhibited similar proliferation indices to WT mice.
Following tamoxifen treatment, the number of proliferating cells observed in WT mice increased 1.8-fold $(P<0.01$, Figures $3 a, c$ and d). This increase was recapitulated in other genotypes of mice (Figures $3 a, c$ and $e-g$ ) but was more pronounced in $\mathrm{Nfkb}^{-1-}$ mice than other groups, where a 2.4-fold increase in proliferating cells was observed $(P<0.0001$ compared with tamoxifen-treated WT mice, Figure 3c). In these animals, proliferating cells were observed between cell positions 2 and 52, with peak proliferative index at cell position 16. a
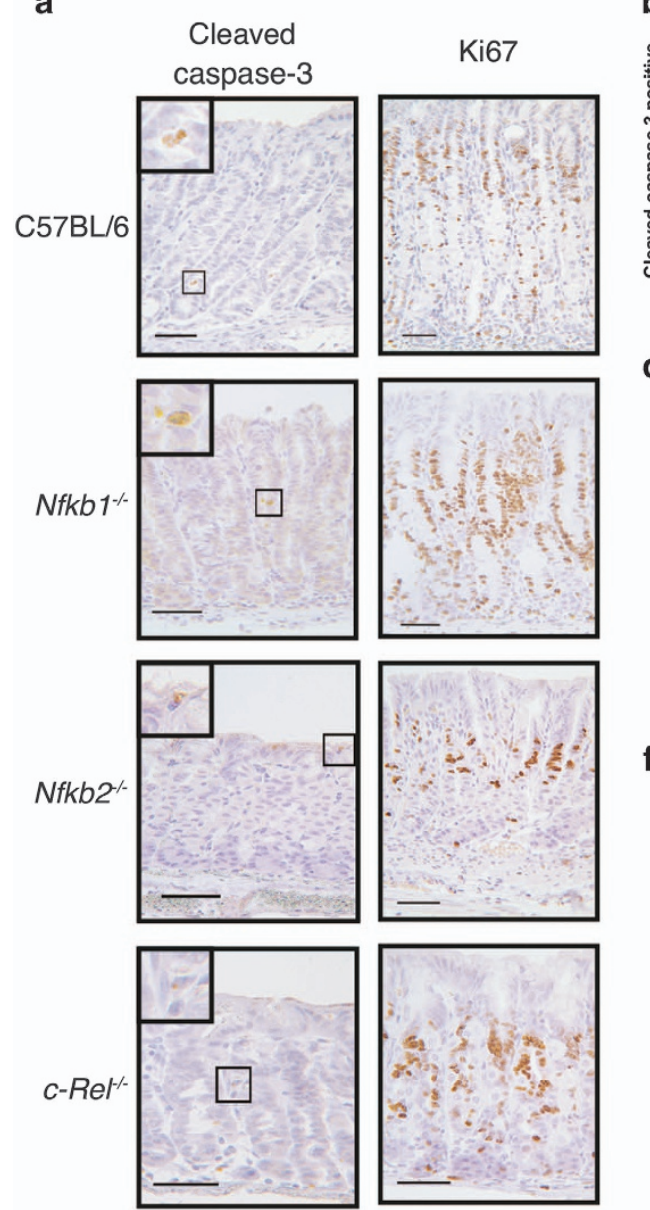

d

f b
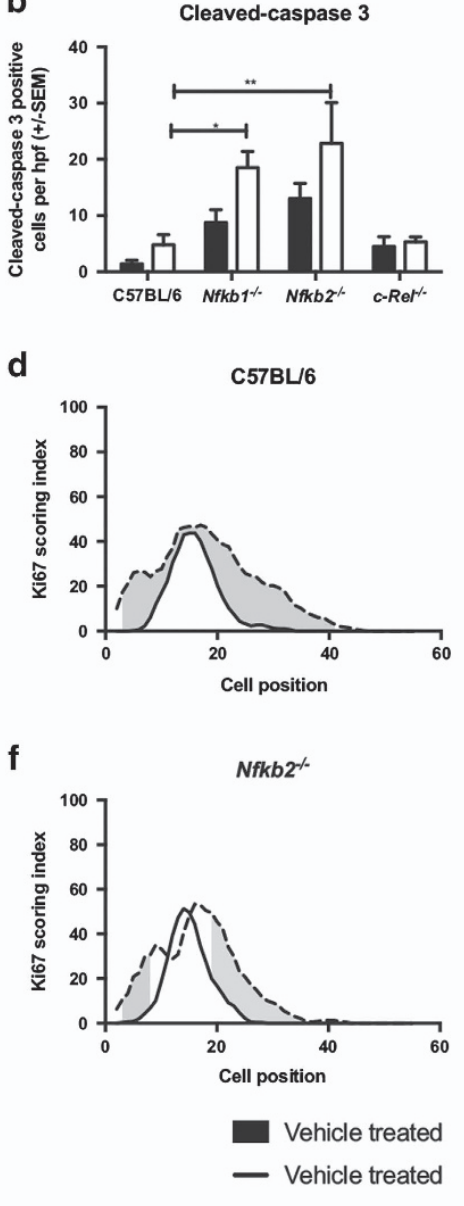

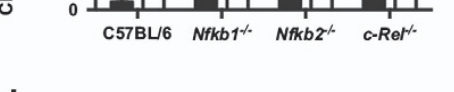

C

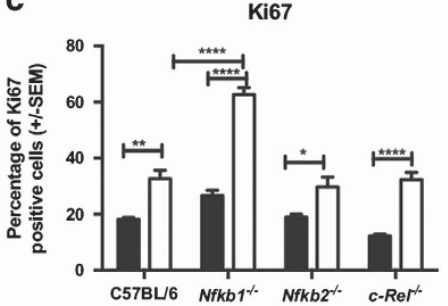

e

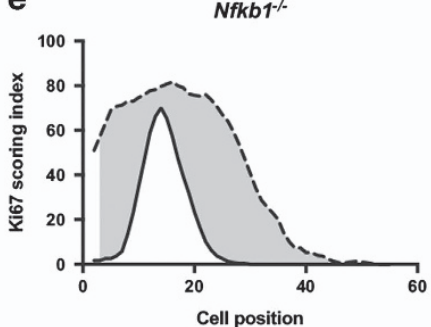

g

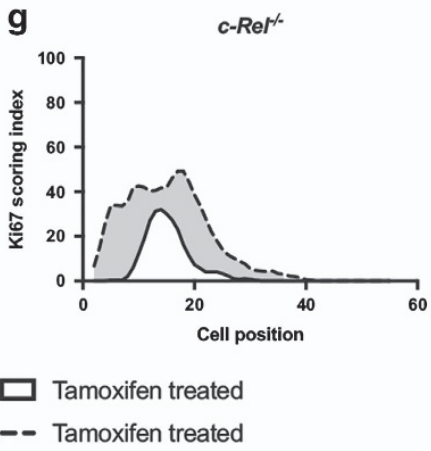

Figure 3 Gastric corpus epithelial cell turnover following tamoxifen administration in WT, $\mathrm{Nfkb}^{-/-}, \mathrm{Nfkb2}^{-1}$ and $\mathrm{c}-\mathrm{Rel}^{--}$mice. (a) Representative photomicrographs of gastric corpus of WT, $\mathrm{Nfkb}^{-1-}, \mathrm{Nfkb2}^{-1-}$ and $\mathrm{c}-\mathrm{Rel}^{-/}$mice treated with $150 \mathrm{mg} / \mathrm{kg}$ tamoxifen. Sections immunostained for expression of cleaved caspase-3 or Ki67. Scale bars $100 \mu \mathrm{m}$. (b) Number of cleaved-caspase 3-positive cells identified per high-power field in mice treated with vehicle or $150 \mathrm{mg} / \mathrm{kg}$ tamoxifen. (c) Percentage of gastric corpus gland cells expressing Ki67 in mice treated with vehicle or $150 \mathrm{mg} / \mathrm{kg}$ tamoxifen. For panels (b and $\mathbf{c}$ ), statistically significant differences tested by two-way ANOVA and Dunnett's test.

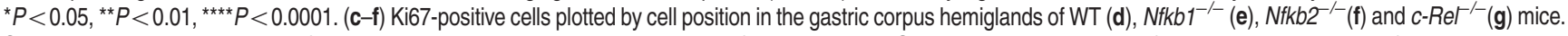
Solid line represents distribution of cells in vehicle-treated mice, broken line tamoxifen-treated mice. Shaded area marks region of gland where distribution of Ki67-positive cells differs significantly in tamoxifen-treated versus vehicle-treated mice, $P<0.05$ by modified median test. $N=5$ for all experimental groups

Figure 4 Gastric corpus expression of $\gamma$-H2AX following tamoxifen administration in WT, Nfkb1 ${ }^{-/-}, \mathrm{Nfkb2}^{-/}$and c-Rel ${ }^{-/}$mice. (a) Representative photomicrographs of gastric corpus of WT, $\mathrm{Nfkb1}^{-/-}, \mathrm{Nfkb2}^{-/}$and $\mathrm{c}-\mathrm{Re}^{-/}$mice treated with $150 \mathrm{mg} / \mathrm{kg}$ tamoxifen. Sections immunostained for expression of $\gamma$-H2AX. Scale bars $100 \mu \mathrm{m}$. (b) Percentage of gastric corpus gland cells expressing $\gamma$-H2AX in mice treated with vehicle or $150 \mathrm{mg} / \mathrm{kg}$ tamoxifen. Statistically significant differences tested by two-way ANOVA and Dunnett's test. ${ }^{* \star} P<0.01,{ }^{* * *} P<0.001$. (b-e) $\gamma$-H2AX-positive cells plotted by cell position in the gastric corpus hemiglands of WT (c), Nfkb1 ${ }^{-/-}$(d), Nfkb2 ${ }^{-1-}$ (e) and $c-\mathrm{Re}^{-1}$ (f) mice. Solid line represents distribution of cells in vehicle-treated mice, broken line tamoxifen-treated mice. Shaded area marks region of gland where distribution of $\gamma$-H2AX cells differs significantly in tamoxifen-treated versus vehicle-treated mice, $P<0.05$ by modified median test. $N=5$ for all groups 
Nfkb1 regulates tamoxifen-induced DNA damage in the gastric epithelium. To investigate the mechanism underlying differences in sensitivity to tamoxifen-induced gastric pathology, we assessed whether there were any aberrant DNA damage responses. Although tamoxifen is best characterized as an anti-estrogen receptor drug, it is also a
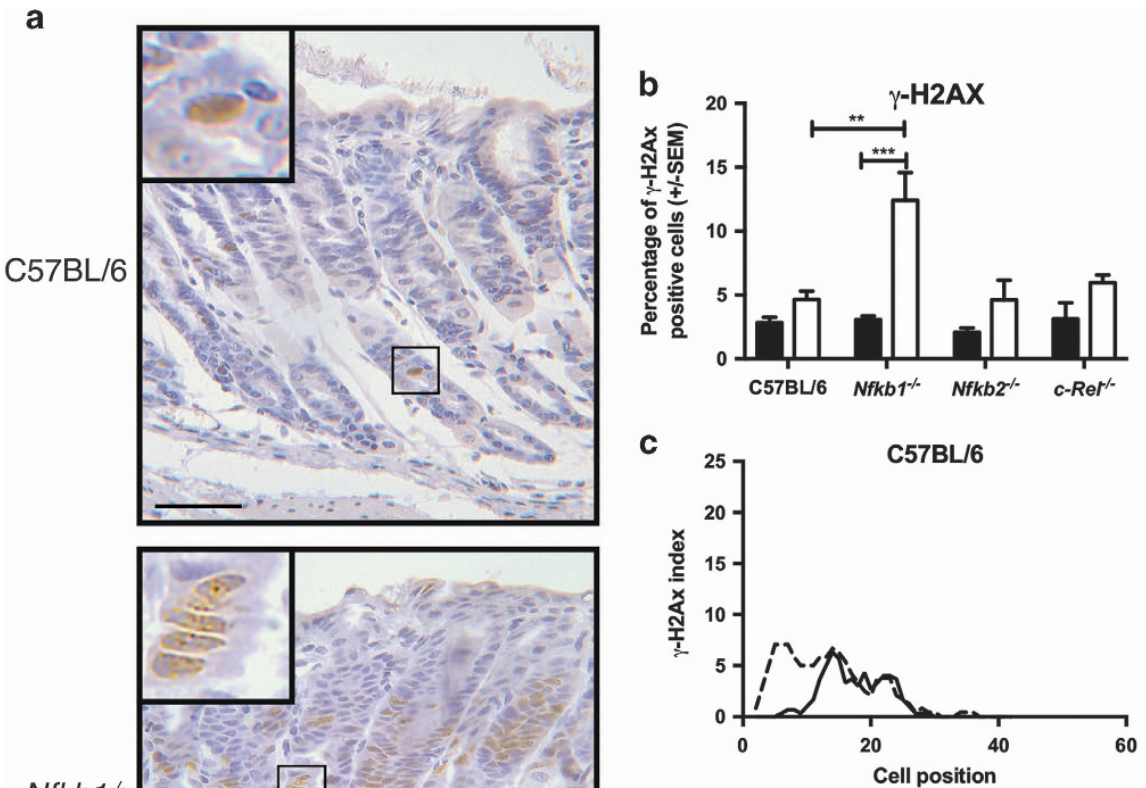

Nfkb1
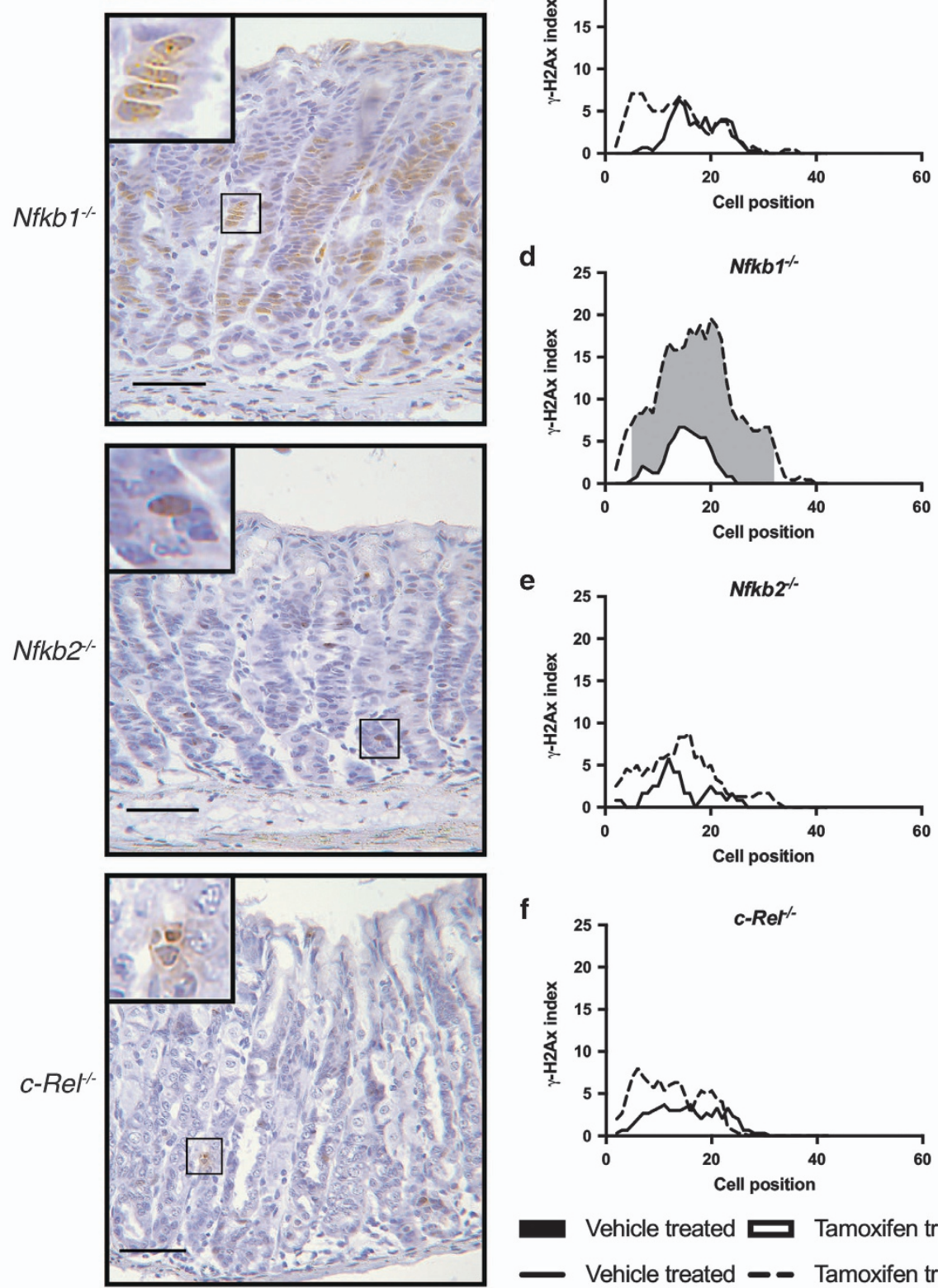

Vehicle treated $\square$ Tamoxifen treated Vehicle treated - - Tamoxifen treated 

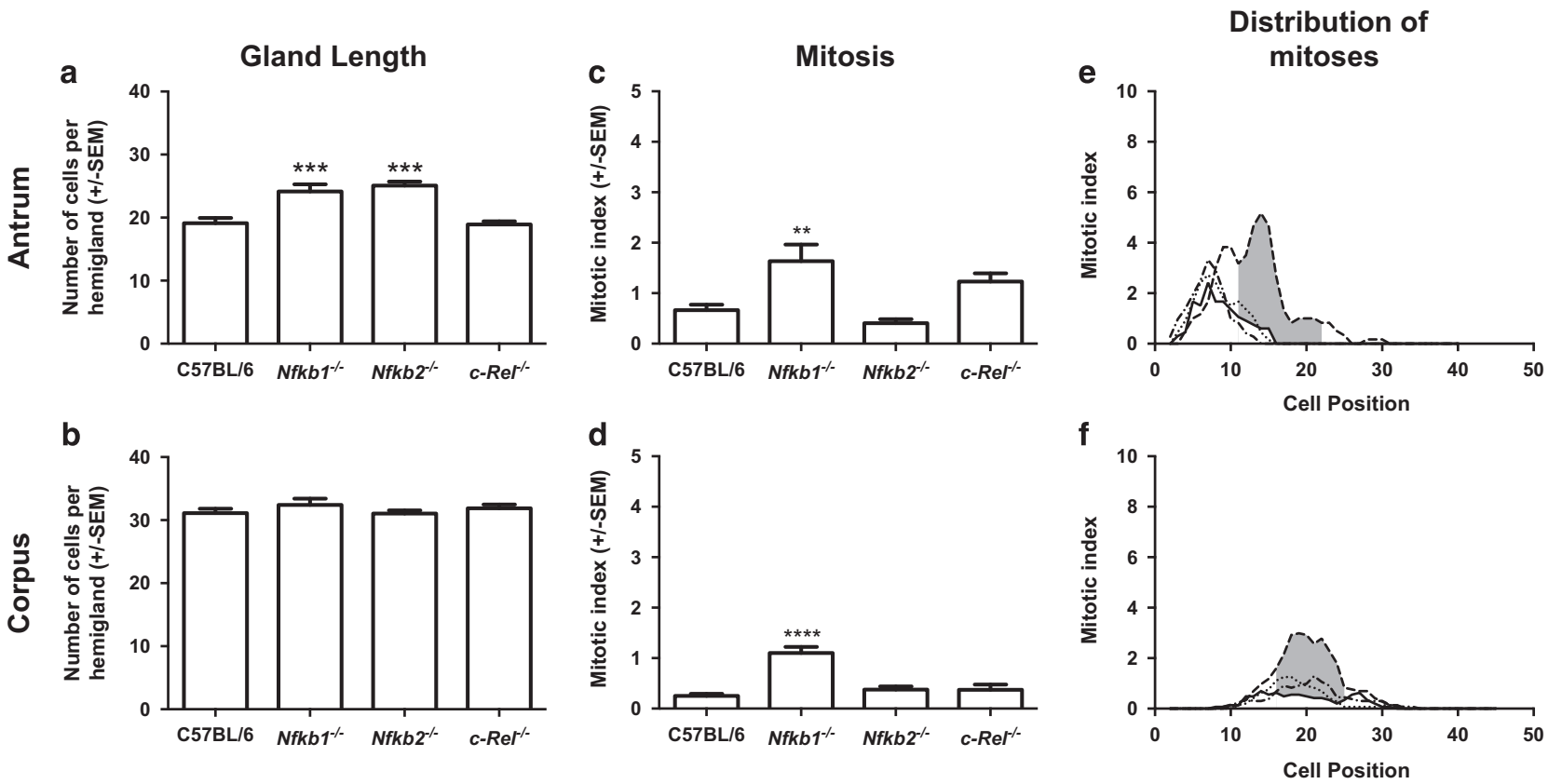

Figure 5 Impact of NF-kB subunit deletion on gastric gland length ( $\mathbf{a}$ and $\mathbf{b}$ ), number of gastric epithelial cells undergoing mitosis (c and $\mathbf{d}$ ) and location of mitoses within the gastric gland (e and $\mathbf{f})$ of untreated mice. Panels $(\mathbf{a}, \mathbf{c}$ and $\mathbf{e})$ represent events in the gastric antral mucosa; panels $(\mathbf{b}, \mathbf{d}$ and $\mathbf{f})$ show data from the gastric corpus. Statistically significant differences tested by one-way ANOVA and Dunnett's test (a-d), ${ }^{* \star} P<0.01,{ }^{* * \star} P<0.001{ }^{* * * *} P<0.0001$. (e and f) Solid line represents distribution of mitotic cells in WT mice, dashed line $\mathrm{Nfkb}^{-/-}$, dotted line $\mathrm{Nfkb}^{-1-}$, dot and dash line $\mathrm{c}-\mathrm{Re}^{-/}$mice. Shaded area marks region of gland where distribution of mitotic cells differs significantly in WT versus Nfkb $^{-1-}$ mice, $P<0.05$ by modified median test. $N=6$ for all experimental groups

genotoxic agent. DNA damage induced by tamoxifen is associated with the formation of tamoxifen/DNA adducts and with the induction of oxidative stress by tamoxifen metabolites. ${ }^{12}$ This mechanism has been hypothesized to be of clinical relevance in patients treated with tamoxifen, who have an increased risk of some malignancies, including endometrial cancer. ${ }^{13}$ We hypothesized therefore that this effect may influence the degree of gastric pathology induced by tamoxifen.

To quantify this, we immunostained tissue sections using a phospho-specific antibody targeting $\gamma$ - $\mathrm{H} 2 \mathrm{AX}$, which reflects a DNA damage response in the cell. In untreated gastric corpus mucosa, $y-\mathrm{H} 2 \mathrm{AX}$ was identified in $2.8 \%$ of WT epithelial cells. All untreated transgenic groups had similar percentages of $\gamma$-H2AX-labeled cells to WT mice (Figures $4 a-f)$. There was a small increase in abundance of $\gamma-\mathrm{H} 2 \mathrm{AX}$ following tamoxifen treatment of WT mice (4.6\%), but this did not reach statistical significance. A similar trend toward increased abundance of $\gamma$ - H2AX was observed in $\mathrm{Nfkb2}^{-1}$ and $\mathrm{c}-\mathrm{Re}^{-1}$ mice administered tamoxifen. In contrast, the percentage of $\gamma-\mathrm{H} 2 \mathrm{AX}$ -

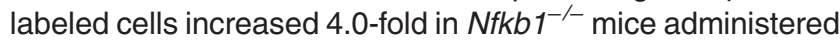
tamoxifen $(P<0.001$, Figure 4b). Excess $\gamma$-H2AX expression occurred over a wide gland area in this strain (between cell positions 5 and 32 of the gastric corpus gland, Figure 4d). In tamoxifen-treated $\mathrm{Nfkb}^{-1-}$ mice, $\mathrm{\gamma}$-H2AX expression was observed between cell positions 2 and 39, with peak $\gamma-\mathrm{H} 2 \mathrm{AX}$ expression observed at cell position 20 (Figure 4d).

Previous studies have suggested that the administration of tamoxifen specifically induced gastric parietal cell death. To characterize which cell types experienced DNA damage in our studies, we performed co-immunofluorescence studies with immunostaining for both $\mathrm{H}^{+} / \mathrm{K}^{+} A T P$ ase and $\gamma-\mathrm{H} 2 \mathrm{AX}$. These assays demonstrated that, while some $\gamma$-H2AX-positive cells were parietal cells, other $\gamma$-H2AX-positive cells did not express $\mathrm{H}^{+} / \mathrm{K}^{+}$ATPase (Supplementary Figure 2). Because of the differences in proliferation indices observed in $\mathrm{Nfkb1}^{-/-}$mice following TAM administration, we also wanted to determine whether DNA damage, identified by $\gamma-\mathrm{H} 2 \mathrm{AX}$ immunostaining, colocalized predominantly with proliferating cells. To do this, we performed $\gamma$-H2AX/Ki67 co-immunostaining. This assay demonstrated that, although a proportion of $\gamma-\mathrm{H} 2 \mathrm{AX}$ stained cells were in S phase following tamoxifen administration, the others did not appear to be proliferating (Supplementary Figure 3).

$\mathrm{Nfkb1}^{-/}$mice also have aberrant responses to $\gamma$-irradiation induced DNA damage. We next wanted to characterize whether the differences identified in $\gamma$-H2AX expression in $\mathrm{Nfkb1}^{-/}$mice were due specifically to altered responses to the genotoxic stress induced by tamoxifen or represented a more generic aberrant response to DNA damage. To address this, we quantified gastric epithelial cell turnover in both the gastric corpus and antrum at baseline and 6 and $48 \mathrm{~h}$ following $12 \mathrm{~Gy} \gamma$-irradiation by cell positional scoring of morphologically apoptotic and mitotic cells. This dose and time points of $\gamma$-irradiation have previously been demonstrated to be optimal for the assessment of DNA damage-induced apoptosis in the stomach, and morphological assessment of $\mathrm{H}+\mathrm{E}$-stained sections correlates well with 
other markers of apoptosis, including cleaved-caspase 3 immunostaining and TUNEL staining. ${ }^{14}$

In untreated age matched, young adult WT mice, gastric antral glands were $19.1( \pm 1.9)$ cells in length on average, while corpus glands were a mean $31.1( \pm 1.7)$ cells long. Deletion of NF- $k$ B subunits did not significantly alter the length of gastric corpus glands, while in the antrum, gastric gland hyperplasia to a mean gland length of 24.2 cells $( \pm 2.6, P<0.01)$ was observed in $\mathrm{Nfkb} 1^{-/}$mice and to 25.1 cells $( \pm 1.6, P<0.01)$ in $\mathrm{Nfkb2}^{-1-}$ mice (Figures $5 \mathrm{a}$ and b).

An average of $0.66 \%( \pm 0.24)$ of antral gland cells were mitotic in untreated WT mice, and these were distributed between cell positions 3 and 15 with peak mitotic index at cell position 7. In $\mathrm{Nfkb}^{-1-}$ mice, the number of mitotic cells observed was higher $(1.6 \pm 0.73 \%, P<0.05$, Figure $5 c)$, and the distribution of mitoses occurred over a wider area (cell positions 4-25), with the position of peak mitotic index shifted up the gland to cell position 14. Statistically significant increases in mitotic indices were observed at cell positions 11-22 in $\mathrm{Nfkb}^{-1}$ compared with WT mice $(P<0.05$, Figure $5 e)$. No statistically significant differences in the number or distribution of mitotic cells were identified in the gastric mucosae of mice lacking NF-kB2 or c-Rel.

In gastric corpus mucosa, $0.25 \%( \pm 0.10)$ of cells were mitotic in WT mice (Figure 5d). These events were distributed between cell positions 10 and 31, with peak mitotic index at cell position 14 (Figures $5 \mathrm{~d}$ and f). In $\mathrm{Nfkb1^{-/ }}$ mice, $1.1 \%$ $( \pm 0.29, P<0.0001)$ of gastric corpus cells were mitotic and mitotic cells were distributed between cell positions 11 and 32 , with peak mitotic index at cell position 19. Increased gastric corpus mitotic index $(P<0.05)$ was observed in $N f k b 1^{-1-}$ mice compared with WT mice between cell positions 16 and 25 (Figures $5 d$ and $f$ ).

In untreated WT mice, $0.17 \%( \pm 0.25)$ of cells in the gastric antrum were identified as morphologically apoptotic; these events were distributed in low numbers from cell position 4 to 12 . Neither the number nor the distribution of apoptotic cells was significantly different in the antrum of untreated $\mathrm{Nfkb}^{-1-}$ mice (Figures 6a, c and e). In the corpus of untreated WT mice, $0.04 \%( \pm 0.04)$ of cells were morphologically apoptotic and were distributed between cell positions 8 and 26. By this measure, the number of apoptotic cells in the gastric corpus was increased 4.8-fold in untreated $\mathrm{Nfkb1}^{-1-}$ mice $(0.19 \% \pm 0.15, \quad P<0.05)$, and the apoptotic cells were distributed over a marginally wider region of the corpus gland than in WT mice (cell positions 5-32) (Figures 6b, d and f).

$\gamma$-Irradiation entirely suppressed mitosis in the gastric tissues of both WT and Nfkb1 $1^{-1-}$ mice at both 6- and 48-h after irradiation. However, $6 \mathrm{~h}$ after $\gamma$-irradiation, the numbers of apoptotic cells identified in both the corpus and antrum of

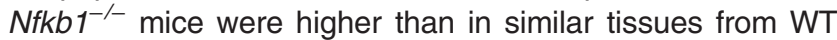
mice (Figures $6 \mathrm{c}$ and $\mathrm{d}$ ). In the antrum, 2.8\% $( \pm 1.1)$ of gastric antral cells were apoptotic in WT mice, with apoptotic cells distributed between cell positions 2 and 17 and peak apoptotic index at cell position 6. Six hours after $\gamma$-irradiation, $4.4 \%$ $( \pm 1.5, P<0.05)$ of antral cells were apoptotic in $N f k b 1^{-1-}$ mice, with apoptotic cells observed between cell positions 2 and 24 and peak apoptotic index at cell position 7. Significantly increased apoptosis was observed in $\mathrm{Nfkb}^{-/-}$mice between cell positions 10 and $17(P<0.05$, Figure $6 \mathrm{~g})$.

Six hours after $\gamma$-irradiation, $0.34 \%( \pm 0.04)$ cells were apoptotic in the gastric corpus of WT mice, compared with $1.8 \%( \pm 0.07)$ cells in $N f k b 1^{-/-}$mice $(P<0.0001)$. Apoptotic cells were distributed between cell positions 9 and 28 in WT mice, with peak apoptotic indices observed at cell positions 13 and 19. In $\mathrm{Nfkb}^{-/-}$mice, apoptosis was observed between cell positions 6 and 33, with peak apoptosis at cell position 18 . Increased apoptosis was observed in the gastric corpus of $N f k b 1^{-/-}$mice between cell positions 9 and $25(P<0.05$, Figure 6h).
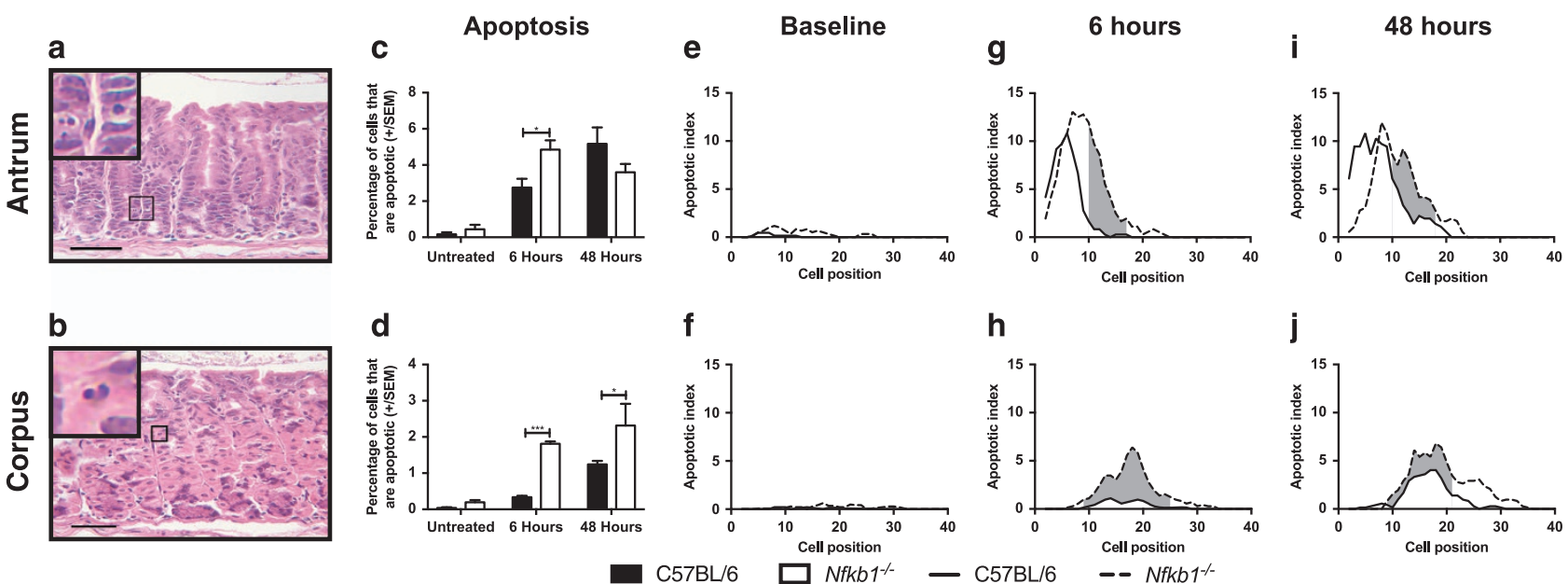

Figure 6 Impact of NF- $\kappa \mathrm{B} 1$ deletion on gastric epithelial apoptosis in untreated and $12 \mathrm{~Gy} \gamma$-irradiated mice 6 and $48 \mathrm{~h}$ after irradiation. (a and $\mathbf{b})$ Representative images of gastric corpus and antrum respectively stained with hematoxylin and eosin, arrows highlight apoptotic epithelial cells. Scale bars $100 \mu \mathrm{m}$. (c and d) Percentage of gastric epithelial cells undergoing apoptosis in gastric antrum and corpus, respectively. Statistically significant differences tested by two-way ANOVA and Dunnett's test. ${ }^{*} P<0.05$, ${ }^{* \star *} P<0.001$. (e-j) Apoptotic cells plotted by cell position in the gastric antrum (e, $\mathbf{g}$ and $\left.\mathbf{i}\right)$ and corpus (f, $\mathbf{h}$ and $\left.\mathbf{j}\right)$ of untreated and irradiated WT and $N f k b 1^{-/-}$mice. Solid lines represent distribution of cells in WT mice, broken lines Nfkb ${ }^{-1-}$ mice. Shaded areas mark regions of glands where distribution of apoptotic cells differs significantly in WT versus Nfkb $1^{-/}$mice, $P<0.05$ by modified median test. $N=6$ for all experimental groups 
Forty-eight hours after $y$-irradiation, the differences in

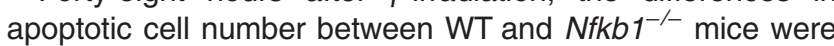
less marked, particularly in the gastric antrum. At this time point, 5.2\% $( \pm 2.0)$ of antral epithelial cells were apoptotic in WT mice, compared with $3.6 \%$ of cells in $N \mathrm{fkb} 1^{-1-}$ mice $(P=0.10$, Figure 6c). Apoptosis was observed in WT mice between cell positions 2 and 20, with peak apoptosis at cell

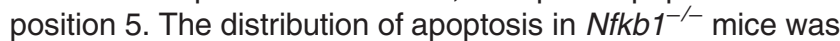
shifted slightly up the antral gland compared with WT mice, with apoptotic cells being observed between cell positions 2 and 23 and peak apoptosis at cell position 8. Increased apoptosis was observed in $N f k b 1^{-1-}$ mice between cell positions 10 and $18(P<0.05$, Figure $6 \mathrm{i})$.

In the gastric corpus, $1.2 \%( \pm 0.09)$ of cells were apoptotic in WT mice $48 \mathrm{~h}$ after $\gamma$-irradiation, compared with $2.3 \%( \pm 0.60)$ in $N f k b 1^{-1-}$ mice $(P<0.05$ Figure $6 \mathrm{~d})$. At this time point, apoptotic cells were observed between cell positions 4 and 30 , with peak apoptosis at cell positions 17 and 18 in WT mice. In

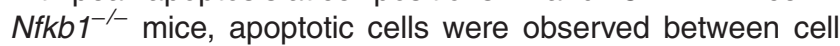
positions 9 and 35, with peak apoptosis at cell position 14 . Increased apoptosis was observed between cell positions 9 and $21(P<0.05$, Figure 6j).

$\mathrm{Nfkb1}^{-/}$animals have primed extrinsic pathway apoptosis mechanisms in the gastric epithelium. To investigate the mechanism underlying the increased gastric epithelial apoptosis in mice lacking $N f k b 1$, we extracted mRNA from mucosal samples of mice either without treatment or $6 \mathrm{~h}$ following $\gamma$-irradiation. We performed real-time PCR assays to quantify the expression of eight regulators of apoptosis that have previously been shown to be under the transcriptional regulation of NF- $K \mathrm{~B}$ signaling. ${ }^{15-21}$ No statistically significant differences in the expression of the inhibitors of apoptosis C-IAP1, c-IAP2 or xIAP were identified (Figures 7a-c) nor were changes in the expression of $\mathrm{p} 53, \mathrm{BCl}-2$ or $\mathrm{BCL}_{\mathrm{XL}}$ observed (Figures 7d-f). In contrast, Fas and FasL expression levels were both upregulated (1.8- and 4.8-fold, $P<0.01$ and $P<0.0001$ respectively, Figures $7 \mathrm{~g}$ and $\mathrm{h}$ ) in the gastric mucosa of untreated $\mathrm{Nfkb} 1^{-1-}$ mice compared with WT mice. Six hours after $\gamma$-irradiation, Fas and FasL transcript abundance increased in WT mice to levels similar to those

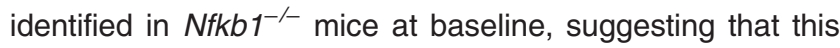
pathway is activated in response to $\gamma$-irradiation.

\section{Discussion}

These data demonstrate that NF- $\kappa \mathrm{B}$ signaling is involved in regulating the development of gastric epithelial metaplasia and atrophy following tamoxifen administration. In this model, the most significant NF- $\kappa \mathrm{B}$ subunit appears to be NF- $\kappa \mathrm{B} 1$, as mice lacking NF- $\kappa \mathrm{B} 2$ and $c-$ Rel demonstrated few differences in response compared with WT mice. This contrasts with previous observations from our own laboratory that have demonstrated differential regulation of $H$. felis-induced gastric preneoplastic pathology in mice lacking NF- $\kappa \mathrm{B} 2$ as well as NF- $\kappa \mathrm{B} 1$.

The differences in gastric epithelial pathology observed in

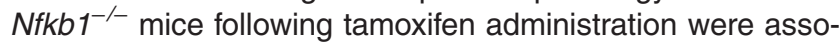
ciated with a more pronounced proliferative response and increased epithelial cell apoptosis. This increase in proliferation was observed throughout the gland. This is consistent with recent reports by Burclaff et $a l^{22}$ that describe the development of a metaplastic progenitor source following tamoxifen-induced dedifferentiation of chief cells.

Further investigation of the DNA damage responses of $\mathrm{Nfkb1^{-/ }}$ mice demonstrated an increased sensitivity to $\gamma$-irradiation-induced epithelial cell apoptosis than WT mice. This suggests that the difference in response to tamoxifen may reflect a more generalized difference in DNA damage responses in these mice, rather than a specific tamoxifenrelated event. This is supported by earlier studies which have shown that, following $\mathrm{\gamma}$-irradiation, $\mathrm{Nfkb} 1^{-1}$ mice exhibited more small intestinal apoptosis than WT mice. ${ }^{23}$

The dynamics of NF- $\kappa \mathrm{B}$ - and p53-mediated signaling in response to DNA damage have been subject to systematic modeling in recent years. ${ }^{24}$ This work has demonstrated that these mechanisms are closely linked and form a complex regulatory network for DNA damage responses. It is therefore unsurprising that abrogation of $\mathrm{NF}-\kappa \mathrm{B}$ signaling pathways leads to altered DNA damage responses. Nonetheless, it is striking that following tamoxifen administration this effect was almost exclusively associated with NF- $\mathrm{BB} 1$ deletion.

We adopted a candidate gene approach to try to identify specific targets of NF- $\kappa$ B signaling that could explain the observed differences in apoptosis. Although there are compromises associated with this approach, we identified potential priming of the CD95/FasL pathway in untreated mice lacking NF- $k \mathrm{~B} 1$. Although this pathway is not the most frequently studied in DNA damage-induced apoptosis, there are both in vitro ${ }^{25}$ and in vivo ${ }^{26}$ studies that demonstrate its role in modulating radiation-induced apoptosis. Further studies that address the functional effect of components of this pathway on tamoxifen-induced gastric lesions may provide further insight into this mechanism.

Previous data have demonstrated that gastric epithelial cells express the estrogen receptor, and hence a direct abrogation of signaling through this receptor is a biologically plausible mechanism for inducing gastric atrophy; however, the similarity of lesions induced in the stomach following tamoxifen with that induced by known protonophores including DMP-777 has also promoted the concept of tamoxifen acting as a direct epithelial cell toxin. ${ }^{10}$ Our DNA damage assays suggest that genotoxic stress may contribute to the gastric lesions induced by tamoxifen. However, further studies investigating the underlying mechanism of tamoxifeninduced gastric murine pathology are required.

We conclude that signaling involving NF-kB1 regulates gastric epithelial pathology in response to a second model of gastric atrophy and metaplasia. As in $H$. felis infection, following tamoxifen administration, signaling mediated by NF- $k B 1$ appears to suppress gastric epithelial cell turnover and DNA damage responses. This is coupled with altered baseline expression of Fas and FasL in mice lacking NF- $k B 1$, which may contribute to excess apoptosis following genotoxic stress. Given that these animals demonstrate differences in susceptibility to both genotoxic stress and susceptibility to gastric preneoplasia, further studies investigating how abrogation of NF- $\kappa \mathrm{B}$ signaling pathways influences chemical carcinogen-induced gastric carcinogenesis would provide interesting insight into the importance of these pathways during gastric carcinogenesis. 

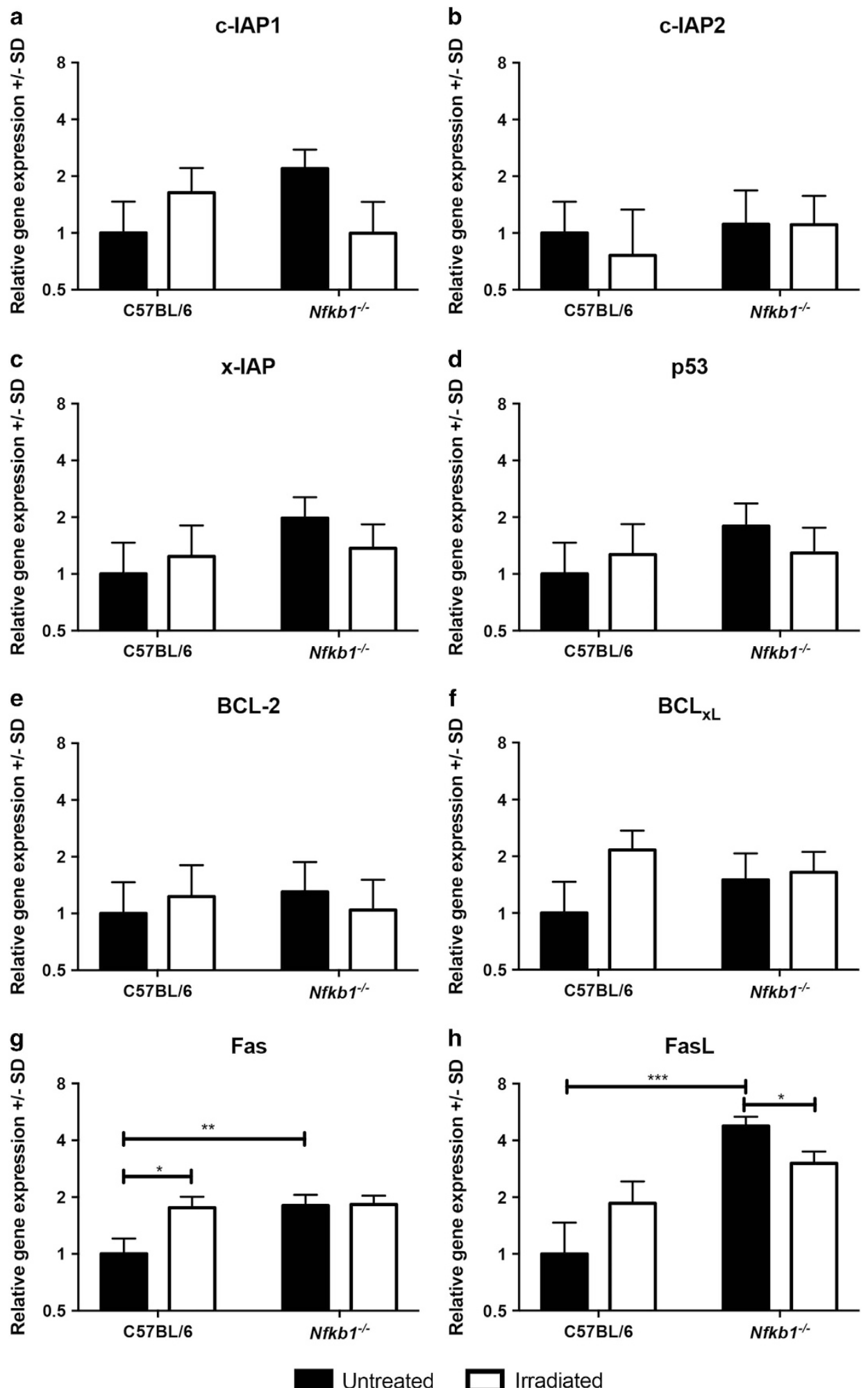

Figure 7 Relative gene expression of specified regulators of apoptosis under transcriptional regulation of NF-kB signaling. Filled bars represent untreated mice, open bars animals culled $6 \mathrm{~h}$ after $12 \mathrm{~Gy} \gamma$-irradiation. Mean and S.D of $\log _{2}$-transformed relative abundance for each transcript are plotted. Statistically significant differences tested by two-way ANOVA and Dunnett's test, ${ }^{\star} P<0.05,{ }^{* \star} P<0.01,{ }^{* *} P<0.001 . N=3$ for all experimental groups. Panels show expression of the following transcripts: (a) $\mathrm{C}$-IAP! (b) c-IAP2, (c) x-IAP, (d) p53, (e) BCL-2, (f) BCL-xL, (g) Fas, (h) FasL 
Table 1 Primers, probes and amplicons for quantitative PCR assays

\begin{tabular}{|c|c|c|c|c|c|c|}
\hline & Target & Forward primer $\left(5^{\prime} \rightarrow 3^{\prime}\right)$ & Reverse primer $\left(5^{\prime} \rightarrow 3^{\prime}\right)$ & $\begin{array}{l}\text { UPL } \\
\text { probe }\end{array}$ & $\begin{array}{l}\text { Amplicon } \\
\text { (bp) }\end{array}$ & Intron (bp) \\
\hline Fas & ENSMUSG00000024778 & TGCAGACATGCTGTGGATCT & CTTAACTGTGAGCCAGCAAGC & \#34 & 60 & 16377 \\
\hline FasL & ENSMUSG00000000817 & ACCGGTGGTATTTTTCATGG & AGGCTTTGGTTGGTGAACTC & \#21 & 117 & 791 \\
\hline C-IAP1 & ENSMUSG00000057367 & GAAGAAAATGCTGACCCTACAGA & CATGACGACATCTTCCGAAC & \#80 & 72 & 4393 \\
\hline C-IAP2 & ENSMUSG00000032000 & GGGGACGATTTAAAGGTATCG & TCGGTTTTACTGCTAGGCTGA & \#5 & 139 & 11412 \\
\hline XIAP & ENSMUSG00000025860 & GCTTGCAAGAGCTGGATTTT & TGGCTTCCAATCCGTGAG & \#25 & 88 & 1334 \\
\hline p53 & ENSMUSG00000059552 & ATGCCCATGCTACAGAGGAG & AGACTGGCCCTTCTTGGTCT & \#78 & 74 & 585 \\
\hline Bcl-2 & ENSMUSG00000057329 & GTACCTGAACCGGCATCTG & GGGGCCATATAGTTCCACAA & \#75 & 76 & 168904 \\
\hline $\mathrm{Bcl}-\mathrm{xL}$ & ENSMUSG00000007659 & TGACCACCTAGAGCCTTGGA & TGTTCCCGTAGAGATCCACAA & \#2 & 68 & 47142 \\
\hline GAPDH & ENSMUSG00000057666 & GGGTTCCTATAAATACGGACTGC & CCATTTTGTCTACGGGACGA & \#52 & 112 & 240 \\
\hline
\end{tabular}

In the current study, we observed no differences between WT and $N f k b 2^{-1-}$ mice. This is in contrast to $H$. felis infection, following which $\mathrm{Nfkb2}^{-1}$ mice were almost entirely protected from gastric epithelial pathology. This contrast suggests that the effects of $N f k b 1$ and $N f k b 2$ deletion on gastric epithelial pathology are mediated through different mechanisms.

\begin{abstract}
Materials and Methods
Mice. All murine procedures were performed at the University of Liverpool Biomedical Services Unit in a specific pathogen-free research facility under appropriate UK Home Office licensing and following University of Liverpool Research Ethics Committee approval.

Animals were maintained with a standard 12-h light/dark cycle and received standard rodent chow and water ad libitum throughout the experimental procedures. Female C57BL/6 WT (WT) mice were purchased from Charles River (Margate, UK) and maintained for a minimum 7-day acclimatization prior to use in experiments. $\mathrm{Nfkb}^{-/-}, \mathrm{Nfkb2}^{-1-}$ and $\mathrm{c}-\mathrm{Re}^{\digamma^{-}}$mice (as previously described ${ }^{27}$ ) were bred and maintained on a C57BL/6 genetic background at the University of Liverpool.
\end{abstract}

Animal procedures. Tamoxifen (Cayman Chemicals, Cambridge Biosciences, Cambridge, UK) was prepared as previously described in ethanol and corn oil. ${ }^{8}$ Groups of at least 5 female mice aged 10-12 weeks were administered either $150 \mathrm{mg} / \mathrm{kg}$ tamoxifen or vehicle via a single intraperitoneal injection. Seventy-two hours later, animals were killed by cervical dislocation, and gastric tissues were harvested for histology.

Whole-body $\gamma$-irradiation was performed by exposure to a Caesium-137 source in a GammaCell closed source irradiator. Groups of at least 6 female mice aged 10-12 weeks were exposed to a single 12 Gy fraction of $\gamma$-irradiation. Animals were returned to standard housing conditions prior to being killed at 6 or $48 \mathrm{~h}$ after procedure by cervical dislocation. Gastric tissues were harvested for histology. In a separate experiment, similar groups of three mice were treated identically prior to cervical dislocation at $6 \mathrm{~h}$. From these animals, the luminal surface of the stomach was scraped to generate gastric mucosa-enriched samples and flash-frozen in liquid nitrogen prior to nucleic acid extraction.

Immunohistochemistry. Standard immunohistochemical techniques were adopted throughout. Heat-induced epitope retrieval was performed for all antigens in sodium citrate buffer, $\mathrm{pH}$ 6.0. Primary antibodies used were rabbit anti- $\mathrm{H}^{+} / \mathrm{K}^{+}$ATPase (Santa Cruz Biotechnology, Heidelberg, Germany, SC-84304), rabbit anti-Ki67 (AB16667, AbCam, Cambridge, UK) and rabbit anti- $\gamma$ H2AX (\#9718, Cell Signalling, New England Biolabs, Hertfordshire, UK). Secondary detection of all antibodies was performed using IMMpress anti-Rabbit polymer (Vector Laboratories, Peterborough, UK) and SigmaFast 3,3'-diaminobenzidine (Sigma-Aldrich, Dorset, UK).

Quantitative histology. Quantitative histology was performed using previously validated cell positional scoring systems for $\mathrm{H}+\mathrm{E}$-stained and immunohistochemically stained tissues. Briefly, well-oriented gastric glands were identified and individual cells were scored morphologically, or based on positive immunostaining, starting with cell position 1 at the base of the gland and extending up the gland to the luminal surface. Each gland unit scored from base to apex of the gland is described as a hemigland; for each gastric corpus section, a total of 30 hemiglands were scored. ${ }^{28}$ Visual analog scoring of gastric preneoplastic lesions was performed as previously described by Rogers et al. ${ }^{11}$ Cleaved-caspase- 3 immunostaining was quantified based on the number of positively stained cells per high-powered field. For this score, 10 non-overlapping fields of gastric mucosa were visualized using a $\times 40$ objective per tissue section. The number of positively stained cells per high-power field was counted, and mean score per section was calculated.

Quantitative real-time PCR. Total RNA was extracted and reverse transcribed using the Roche Highpure RNA Tissue Kit and Transcriptor Reverse Transcription Kits, respectively. Real-Time PCR was performed on a Roche LightCycler 488 instrument, and assays were designed using the Roche Universal Probe Library. Details of primers, probes and amplicons are included in Table 1. All real-time PCR reagents were sourced from Roche UK, Burgess Hill, UK.

Statistics. Statistical analyses were performed using GraphPad Prism 7 (Graphpad Software, La Jolla, CA, USA). Data were analyzed with two-tailed, two-way Student's $t$-test or two-way ANOVA and Dunnett's post hoc analyses as appropriate. Differences in cell positional distributions were assessed using a modified median test as previously described. ${ }^{29}$

\section{Conflict of Interest}

The authors declare no conflict of interest.

Acknowledgements. We thank Dr Jorge Caamano and Bristol Myers Squibb for donating the $\mathrm{Nfkb2}^{-/}$mouse colony and $\mathrm{Dr}$ Jorge Caamano for providing the colonies of $\mathrm{Nfkb}^{-/}$and $\mathrm{c}-\mathrm{ReF}^{-/}$mice. MDB was funded by a CORE/British Society of Gastroenterology Development Grant and Wellcome Trust/University of Liverpool Institutional Strategic Support Fund grant under grant agreement number: 097826/Z/ 11/Z. MDB and DMP were supported by a North West Cancer Research project grant. MDB, JMW, RH and DMP were supported by the European Council's Seventh Framework Programme (FP7/2007-2013) under grant agreement number 305564 (SysmedlBD).

1. Graham DY. Helicobacter pylori update: gastric cancer, reliable therapy, and possible benefits. Gastroenterology 2015; 148: 719-731 e713.

2. Correa P, Haenszel W, Cuello C, Tannenbaum S, Archer M. A model for gastric cancer epidemiology. Lancet 1975; 306: 58-60.

3. Fox JG, Sheppard BJ, Dangler CA, Whary MT, Ihrig M, Wang TC. Germ-line p53-targeted disruption inhibits Helicobacter-induced premalignant lesions and invasive gastric carcinoma through down-regulation of Th1 proinflammatory responses. Cancer Res 2002; 62: 696-702.

4. Burkitt MD, Duckworth CA, Williams JM, Pritchard DM. Helicobacter pylori-induced gastric pathology: insights from in vivo and ex vivo models. Dis Models Mech 2017; 10: 89-104.

5. Merga YJ, O'Hara A, Burkitt MD, Duckworth CA, Probert CS, Campbell BJ et al. Importance of the alternative NF-kappaB activation pathway in inflammation-associated gastrointestinal carcinogenesis. Am J Physiol Gastrointest Liver Physiol 2016; 310: G1081-G1090.

6. Burkitt MD, Williams JM, Duckworth CA, O'Hara A, Hanedi A, Varro A et al. Signaling mediated by the NF-kappaB sub-units NF-kappaB1, NF-kappaB2 and c-Rel differentially regulate Helicobacter felis-induced gastric carcinogenesis in C57BL/6 mice. Oncogene 2013; 32: 5563-5573. 
7. Williams JM, Duckworth CA, Watson AJ, Frey MR, Miguel JC, Burkitt MD et al. A mouse model of pathological small intestinal epithelial cell apoptosis and shedding induced by systemic administration of lipopolysaccharide. Dis Models Mech 2013; 6: 1388-1399.

8. Huh WJ, Khurana SS, Geahlen JH, Kohli K, Waller RA, Mills JC. Tamoxifen induces rapid, reversible atrophy, and metaplasia in mouse stomach. Gastroenterology 2012; 142: 21-24 e27.

9. Sigal M, Rothenberg ME, Logan CY, Lee JY, Honaker RW, Cooper RL et al. Helicobacter pylori activates and expands Lgr5(+) stem cells through direct colonization of the gastric glands. Gastroenterology 2015; 148: e1321.

10. Saenz JB, Burclaff J, Mills JC. Modeling murine gastric metaplasia through tamoxifen-induced acute parietal cell loss. Methods Mol Biol 2016; 1422: 329-339.

11. Rogers AB. Histologic scoring of gastritis and gastric cancer in mouse models. Methods $\mathrm{Mol}$ Biol 2012; 921: 189-203.

12. Phillips DH. Understanding the genotoxicity of tamoxifen? Carcinogenesis 2001; 22: 839-849.

13. Hu R, Hilakivi-Clarke L, Clarke R. Molecular mechanisms of tamoxifen-associated endometrial cancer (review). Oncol Lett 2015; 9: 1495-1501.

14. Przemeck SMC, Duckworth CA, Pritchard DM. Radiation-induced gastric epithelial apoptosis occurs in the proliferative zone and is regulated by p53, bak, bax, and bcl-2. Am J Physiol Gastrointest Liver Physiol 2007; 292: G620-G627.

15. Wang CY, Mayo MW, Korneluk RG, Goeddel DV, Baldwin AS Jr.. NF-kappaB antiapoptosis: induction of TRAF1 and TRAF2 and c-IAP1 and c-IAP2 to suppress caspase-8 activation. Science 1998; 281: 1680-1683.

16. Van Themsche C, Chaudhry P, Leblanc V, Parent S, Asselin E. XIAP gene expression and function is regulated by autocrine and paracrine TGF-beta signaling. Mol Cancer 2010; 9: 216.

17. Liu F, Bardhan K, Yang D, Thangaraju M, Ganapathy V, Waller JL et al. NF-kappaB directly regulates Fas transcription to modulate Fas-mediated apoptosis and tumor suppression. J Biol Chem 2012; 287: 25530-25540.

18. Novac N, Baus D, Dostert A, Heinzel T. Competition between glucocorticoid receptor and NFkappaB for control of the human FasL promoter. FASEB J 2006; 20: 1074-1081.

19. Wang X, Belguise K, Kersual N, Kirsch KH, Mineva ND, Galtier F et al. Oestrogen signalling inhibits invasive phenotype by repressing RelB and its target BCL2. Nat Cell Biol 2007; 9: 470-478.

20. Yu M, Tong X, Qi B, Qu H, Dong S, Yu B et al. Berberine enhances chemosensitivity to irinotecan in colon cancer via inhibition of NFkappaB. Mol Med Rep 2014; 9: 249-254.

21. lannetti A, Ledoux AC, Tudhope SJ, Sellier H, Zhao B, Mowla S et al. Regulation of p53 and $\mathrm{Rb}$ links the alternative NF-kappaB pathway to EZH2 expression and cell senescence. PLoS Genet 2014; 10: e1004642.
22. Burclaff J, Osaki LH, Liu D, Goldenring JR, Mills JC. Targeted apoptosis of parietal cells is insufficient to induce metaplasia in stomach. Gastroenterology 2017; 152: 762-766 e767.

23. Wang Y, Meng A, Lang H, Brown SA, Konopa JL, Kindy MS et al. Activation of nuclear factor $\kappa B$ in vivo selectively protects the murine small intestine against ionizing radiationinduced damage. Cancer Res 2004; 64: 6240-6246.

24. Poltz R, Naumann M. Dynamics of p53 and NF-kappaB regulation in response to DNA damage and identification of target proteins suitable for therapeutic intervention. BMC Syst Biol 2012; 6: 125.

25. Rehemtulla A, Hamilton CA, Chinnaiyan AM, Dixit VM. Ultraviolet radiation-induced apoptosis is mediated by activation of CD-95 (Fas/APO-1). J Biol Chem 1997; 272: 25783-25786.

26. Bang B, Gniadecki R, Larsen JK, Baadsgaard O, Skov L. In vivo UVB irradiation induces clustering of Fas (CD95) on human epidermal cells. Exp Dermatol 2003; 12. 791-798.

27. Burkitt MD, Hanedi AF, Duckworth CA, Williams JM, Tang JM, O'Reilly LA et al. NF-kappaB1, NF-kappaB2 and c-Rel differentially regulate susceptibility to colitis-associated adenoma development in C57BL/6 mice. J Pathol 2015; 236: 326-336.

28. Duckworth CA, Burkitt MD, Williams JM, Parsons BN, Tang JM, Pritchard DM. Murine models of Helicobacter (pylori or felis)-associated gastric cancer. Curr Protoc Pharmacol 2015; 69 : 1434 11-14 3435.

29. ljiri K, Potten CS. Response of intestinal cells of differing topographical and hierarchical status to ten cytotoxic drugs and five sources of radiation. Br J Cancer 1983; 47: 175-185.

(c) (i) Cell Death and Disease is an open-access journal published by Nature Publishing Group. This work is licensed under a Creative Commons Attribution 4.0 International License. The images or other third party material in this article are included in the article's Creative Commons license, unless indicated otherwise in the credit line; if the material is not included under the Creative Commons license, users will need to obtain permission from the license holder to reproduce the material. To view a copy of this license, visit http://creativecommons.org/licenses/by/4.0/

(C) The Author(s) 2017

Supplementary Information accompanies this paper on Cell Death and Disease website (http://www.nature.com/cddis) 